\title{
Electromagnetic field versus circuit weight training on bone mineral density in elderly women
}

This article was published in the following Dove Press journal:

Clinical Interventions in Aging

9 March 2015

Number of times this article has been viewed

Hany Farid Eid Morsy Elsisi'

Gihan Samir Mohamed

Mousa'

Mohamed Taher Mahmoud

ELdesoky ${ }^{2}$

'Department of Physical Therapy for Cardiovascular/Respiratory Disorder and Geriatrics, ${ }^{2}$ Department of Basic Science, Faculty of Physical Therapy,

Cairo University, Cairo, Egypt
Correspondence: Mohamed Taher Mahmoud ELdesoky

Department of Basic Science, Faculty of Physical Therapy, Cairo University, I4 Abd EL Hafez Ahmed, District 8, Nasr City, Cairo, Egypt

Tel +20 I00 5192745

Email mohamedtaher8@yahoo.com
Background and purpose: Osteoporosis is a common skeletal disorder with costly complications and a global health problem and one of the leading causes of morbidity and mortality worldwide. Magnetic field therapy and physical activity have been proven as beneficial interventions for prevention and treatment of osteoporosis. The purpose of this study was to compare the response of bone mineral content and bone mineral density (BMD) in elderly women to either low-frequency low-intensity pulsed magnetic field (LFLIPMF) or circuit weight training (CWT) on short-run basis (after 12 weeks).

Patients and methods: Thirty elderly women, aged 60-70 years, were randomly assigned into two groups (magnetic field and CWT) ( $\mathrm{n}=15$ each group). The session was performed three times per week for magnetic field and CWT groups, for 12 weeks. BMD and bone mineral content of lumbar spine (L2-L4) and femoral neck, trochanter, and Ward's triangle were evaluated before and after 12 weeks of treatment.

Results: Both magnetic field and CWT for 12 weeks in elderly women seem to yield beneficial and statistically significant increasing effect on BMD and bone mineral content $(P<0.05)$. But magnetic field seems to have more beneficially and statistically significant effect than does CWT.

Conclusion: It is possible to conclude that LFLIPMF and CWT programs are effective modalities in increasing BMD but LFLIPMF is more effective in elderly women.

Keywords: magnetic field, circuit weight training, bone mineral density, elderly women, bone mineral content, bone mass

\section{Introduction}

Aging is associated with body composition changes, such as increase and redistribution of adipose tissue and a decrease in bone and muscle mass in the fourth decade of life. These changes affect the health of the subjects because they are associated with chronic disease and geriatric syndromes. ${ }^{1}$

The electromagnetic field influences the metabolism of bone. ${ }^{2}$ Some studies have reported the useful effect of electromagnetic field on the concentration of calcium in blood and bone mass (BM), ${ }^{3-5}$ but other studies have reported that electromagnetic field has no such effect..$^{6-10}$ There is a contradiction regarding the effect of electromagnetic field on BM.

Circuit resistance training is an exercise program that has beneficial effects on the cardiovascular system and on improving muscular strength. Such training comprises arrangement, normally 10-15, of safety activities for distinctive body parts. For each one, $12-15$ repetitions, utilizing unobtrusive weights $(40 \%-60 \%$ of one-repetition maximum [1RM]), are done. Each activity is commonly finished within 30-40 seconds. The subject moves rapidly, starting with one activity, then moving on to the next with 
a rest of 15-30 seconds between stations. Relying on the level of fitness, the circuit training is repeated one to three times. In this way, circuit resistance training takes around half an hour to finish an activity session. ${ }^{11}$ Some studies have demonstrated that the circuit training enhances pulmonary ventilation, $\mathrm{O}_{2}$ consumption, and functional capacity. Furthermore, it improves muscular strength and physical endurance. ${ }^{12-15}$

Strength training is one of the most frequent types of exercise programs applied in order to improve BM in elderly people. The increased mechanical stress on the bone provided by this type of training has been demonstrated as a causal factor of osteogenesis. ${ }^{16}$

Peak BM is defined as the highest level of bone mineral density (BMD) or bone mineral content (BMC) or BM reached during life. These are all estimations of the amount of mineralized bone. BM is a more generalized term when describing the amount of mineral, BMC the amount of mineral measured within the scanned skeletal region, and BMD the amount of mineral measured within the scanned skeletal region but partially adjusted for the bone size. ${ }^{17}$ Bone mineral status is affected by changes in force, hormones, and diet. ${ }^{18}$ Therefore, resistance training is useful for the improvement of $\mathrm{BMC}$ and bone and muscular strength. ${ }^{19}$

To our best knowledge, enough data are not available comparing the effects of electromagnetic field and circuit resistance training on BMD and BMC. This study was therefore designed to compare the effects of electromagnetic field and circuit weight training (CWT) on BMD and BMC in elderly women.

\section{Patients and methods}

\section{Subjects}

Thirty sedentary elderly women whose age ranged from 60 to 70 years were screened and selected randomly from outpatient clinic, Faculty of Physical Therapy, Cairo University, to participate in this study. The characteristics of the participants are shown in Table 1. The study was approved by the ethics committee of the Faculty of Physical Therapy, Cairo University. All patients signed the informed

Table I Characteristics of the participants

\begin{tabular}{lll}
\hline Characteristics & $\begin{array}{l}\text { Electromagnetic } \\
\text { field group }\end{array}$ & $\begin{array}{l}\text { Circuit weight } \\
\text { training group }\end{array}$ \\
\hline Age (year) & $64.73 \pm 3.08$ & $65.13 \pm 2.44$ \\
Weight $(\mathrm{kg})$ & $84.13 \pm 8.52$ & $85.4 \pm 7.82$ \\
Height $(\mathrm{cm})$ & $157.73 \pm 4.23$ & $159.26 \pm 7.14$ \\
BMI $\left(\mathrm{kg} / \mathrm{m}^{2}\right)$ & $33.76 \pm 2.56$ & $33.86 \pm 1.86$ \\
\hline
\end{tabular}

consent form, agreeing to participation and publication of the results of the study.

Inclusion criteria were as follows: none of them has any other bone disease; all of them receive oral supplementation of calcium, referred by physician, and had an inactive lifestyle for at least the previous 6 months. Exclusion criteria were body mass index (BMI) $\geq 40 \mathrm{~kg} / \mathrm{m}^{2}$, age over 70 or less than 60 years, smoking, severe retinopathy, nephropathy, and neuropathy, serious cardiovascular or cerebrovascular diseases, and severe musculoskeletal problems restricting any physical activity. Women receiving medications such as anticonvulsants and glucocorticoids that affected BMD were also excluded.

Initial medical screening was performed for each participant by the physician; clinical history was documented for all participants. Study protocol and the objectives of the study were thoroughly explained to all participants, who were asked to maintain their pharmacological treatment, regular diet, and normal daily activities and lifestyle throughout the study.

To avoid a type II error, a preliminary power analysis (power $[1-\beta$ error probability $]=0.8, \alpha=0.05$, effect size $=0.5$ ) determined a sample size of 30 for this study. This effect size was chosen because it yielded a realistic sample size. ${ }^{20}$

To avoid bias, participants' random assignments were performed through two stages: first, colleague physical therapists who were working in the outpatient clinics of the Faculty of Physical Therapy, Cairo University, reported all persons who fulfilled the inclusion criteria of the study and had no exclusion criteria; second, after medical counseling, participants were randomly assigned to either magnetic field or CWT group by opening an opaque envelope prepared by an independent subject with random number generation. Participants were randomly assigned to two equal groups: group A $(n=15)$ received electromagnetic field and group B $(n=15)$ received CWT. They participated in the study for 12 weeks (three sessions/week).

\section{Outcome measures}

Both groups underwent an identical battery of tests: baseline (pretreatment) and after-treatment program (3 months posttreatment). The evaluated parameters include BMD and BMC of femoral neck, trochanter, Ward's triangle, and lumbar spine (L2-L4). The assessors were initially blinded to the participants' treatment assignments. All the subjects in the two groups were advised to continue their medications regimen, diets, and daily living physical activity level until the end of the study. 


\section{Evaluation parameters}

\section{The anthropometric characteristics of women}

Body weight was measured in light indoor clothes using a calibrated clinical weight scale, and patient height without shoes was measured using a wall-mounted stadiometer. BMI was calculated as the weight (in kilograms) divided by the height (in meters) squared.

\section{Assessment of bone mineral density}

Dual-energy $\mathrm{X}$-ray absorptiometry

Dual-energy X-ray absorptiometry (DXA; Norland, London, UK) scans are most commonly used to assess BMD. Bone density of the hip, lumbar spine, and total body can be done using DXA; it has a low radiation dose, takes less scanning time, and has great precision and accuracy. ${ }^{21}$ Each subject in both groups will be evaluated before and after 3 months of treatment by DXA (for measuring bone density of neck femur, and lumbar spine. It is the standard technique of measuring BMC using a very low dose of radiation while producing BMD of acceptable precision using BMC (in grams) by area of bone measured (in centimeter squared). Test-retest reliability of the DXA measures based on test-retest using ten subjects resulted in high intraclass correlation coefficient (ICC) for BMC and BMD. The ICC for BMC of neck of femur was 0.98 , for greater trochanter 0.96 , for L2 0.98 , for L3 0.97, and for L4 0.95, and the ICC for BMD of neck of femur was 0.97 , for greater trochanter 0.98 , for Ward's triangle 0.95, for L2 0.97, for L3 0.96, and for L4 0.97.

\section{Instrumentation used for treatment} ASA magnetic field (Automatic PMT Quattro Pro)

ASA magnetic field is a device for magnetotherapy (its model is Automatic PMT Quattro Pro and its serial number is 00001543). It consists of an appliance, motorized bed, and solenoids. The appliance must be connected to electrical mains supplying $230 \mathrm{~V} \pm 10 \%$ at a frequency of 50 or $60 \mathrm{~Hz}$ with earth connection. The intensity and spatial lay out of the generated magnetic field depend on the type of solenoid used. The appliance is capable of generating on the connected solenoid pulsating magnetic fields with a pulse repetition frequency of up to $100 \mathrm{~Hz}$. The appliance, motorized bed, and solenoids are built to operate correctly in a room at a temperature between $0^{\circ} \mathrm{C}$ and $40^{\circ} \mathrm{C}$ and relative humidity from $30 \%$ to $75 \%$.

\section{Weight machines}

The following weight machines were used in our study: Circuit Master CM 240 Latissimus Pulldown, Circuit Master
CM 242 Low Row, FW 1216 40-Degree Back Extension, FW 1212 Abdominal Isolator, FW 1220 Seated Preacher Curl, Circuit Master CM 422 Leg Extension, LX 740 40-Degree Leg Press, Circuit Master CM 434 Prone Leg Curl, and S100 Standing Calf, and ProForm 350 Treadmill (all from Body Masters Sports Industries, Rayne, LA, USA).

\section{Interventions}

Both treatment programs were conducted for participants three times per week for 12 weeks in the outpatient clinic, Faculty of Physical Therapy, Cairo University.

\section{Electromagnetic field}

Subjects received their medications plus low-frequency, lowintensity pulsed electromagnetic field (PEMF) therapy three times per week for 3 months. The therapy session involved the following:

The subject was placed in a comfortable supine position over the motorized bed.

The appliance was connected to electrical mains supplying $230 \mathrm{~V} \pm 10 \%$.

The solenoids were adjusted to be over the lumbar and hip regions.

The options of the appliance were adjusted to very low frequency $(33 \mathrm{~Hz})$ and very low intensity (50 Gauss), for 30 minutes, according to the manual of installation.

\section{Circuit weight training program}

The exercise program was determined in accordance with the American College of Sport Medicine (ACSM) guidelines. Sufficient warm-up and cooldown (about 5-10 minutes) in the form of stretching of major muscle groups, flexibility movements, active movements of limbs, breathing exercises, and walking at low intensity (50\% of maximum heart rate) were performed before and after CWT. Also, sufficient time was taken in familiarizing the participants in CWT group with the resistance training machines by doing one set of each exercise on different weight machines, which was repeated 8-10 times.

The participants in group B were encouraged to have sweet eatable or drinkable things during training to compensate for probable hypoglycemic episodes. They also were advised not to eat heavy meals at least 2 hours before training.

CWT exercises program was performed 30-38 minutes. Closely supervised training techniques were performed by the participants of this group after proper warm-up to minimize the risk of musculoskeletal injuries. The program started and 
Table 2 Circuit weight training program

\begin{tabular}{|c|c|c|c|c|c|}
\hline Week & $\begin{array}{l}\text { Warm-up } \\
\text { (minutes) }\end{array}$ & Intensity & $\begin{array}{l}\text { Recovery interval } \\
\text { (60\%-65\% MHR) } \\
\text { on treadmill (s) }\end{array}$ & Repeat & $\begin{array}{l}\text { Cool down } \\
\text { (minutes) }\end{array}$ \\
\hline $\mathrm{I}$ & 5 & $60 \%-65 \%$ of IRM & 30 & $\mathrm{I}-2$ sets for 10 repetitions & 5 \\
\hline 2 & 5 & $60 \%-65 \%$ of IRM & 30 & $\mathrm{I}-2$ sets for 10 repetitions & 5 \\
\hline 3 & 5 & $60 \%-65 \%$ of IRM & 30 & $\mathrm{I}-2$ sets for 10 repetitions & 5 \\
\hline 4 & 5 & $60 \%-65 \%$ of IRM & 30 & $\mathrm{I}-2$ sets for 10 repetitions & 5 \\
\hline 5 & 5 & $70 \%-75 \%$ of IRM & 30 & 3 sets for 8 repetitions & 5 \\
\hline 6 & 5 & $70 \%-75 \%$ of IRM & 30 & 3 sets for 8 repetitions & 5 \\
\hline 7 & 5 & $70 \%-75 \%$ of IRM & 30 & 3 sets for 8 repetitions & 5 \\
\hline 8 & 5 & $70 \%-75 \%$ of IRM & 30 & 3 sets for 8 repetitions & 5 \\
\hline 9 & 5 & $75 \%-80 \%$ of IRM & 30 & 3 sets for 10 repetitions & 5 \\
\hline 10 & 5 & $75 \%-80 \%$ of IRM & 30 & 3 sets for 10 repetitions & 5 \\
\hline 11 & 5 & $75 \%-80 \%$ of IRM & 30 & 3 sets for 10 repetitions & 5 \\
\hline 12 & 5 & $75 \%-80 \%$ of IRM & 30 & 3 sets for 10 repetitions & 5 \\
\hline
\end{tabular}

Abbreviations: MHR, maximum heart rate; IRM, one-repetition maximum.

progressed gradually in intensity. The intensity progress for CWT group followed a stepwise manner in which there was a gradual increase by $2.5 \%$ of $1 \mathrm{RM}$ every 2 weeks. Moderate resistance was used in which $60 \%-65 \%$ of $1 \mathrm{RM}$ was used during the 1 st month, and then the intensity was increased to $70 \%-75 \% 1 \mathrm{RM}$ in the $2 \mathrm{nd}$ month, and finally, the intensity was increased to $75 \%-80 \% 1 \mathrm{RM}$ during the last month. The training program started with one to two sets of ten repetitions of eight different exercises for back, abdomen, and lower body during the $1 \mathrm{st}$ month, and then the repetition was increased to three sets of the eight repetitions of eight different exercises for back, abdomen, and lower body during the 2nd month, and finally, reaching three sets of ten repetitions of eight different exercises for back, abdomen, and lower body during the 3rd month (Table 2). A 30-second walking on treadmill at moderate intensity was performed, with $60 \%-65 \%$ of the maximum heart rate as a recovery period between each two successive sets. ${ }^{22}$ The following exercises were performed: back extension exercise, abdominal curl exercise, seated row, leg curl, leg extension, leg press, latissimus pulldown, and standing calf raise.

All 30 participants showed good adherence and acceptance to complete the program. No serious adverse effect was reported in either group.

\section{Statistical analysis}

Data were analyzed descriptively and with a $2 \times 2$ mixedmodel MANOVA (multivariate analysis of variance) and subsequent post hoc $2 \times 2$ univariate ANOVA (analysis of variance) using the SPSS version 17 software, with $P$-value set at 0.05 . Bonferroni corrections were made to the significance level for post hoc univariate analyses to control for type I error. Independent variables were time (within subjects) with two levels (pretreatment and posttreatment) and group (between subjects) with two levels (electromagnetic field and CWT). The dependent variables were BMC and BMD for femoral neck, trochanter, Ward's triangle, and lumbar spine (L2-L4). Shapiro-Wilk test and Levene's test were used to test the normality of the data and the equality of variances, respectively.

\section{Results}

Statistical diagnostic tests revealed no violations of the assumptions of normality and homogeneity of variance for any of the dependent variables. Descriptive statistics of BMC and $\mathrm{BMD}$ of different regions are presented in Table 3 . The rate of adherence of the participants to the sessions was $100 \%$ for both groups. There was no significant difference between the two groups in all pretreatment dependent variables $(P>0.05)$. The overall MANOVA yielded a significant main effect for both time $(<0.0001)$ and group $(0.007)$ and a significant time $\times$ group interaction effect $(P<0.0001)$. Post hoc univariate ANOVAs for each of the dependent variables revealed significant main effects for both time and group and significant time $\times$ group interaction effect for all BMC and BMD in different regions (Table 4).

Subjects in both groups improved in their BMC and BMD of neck of femur after treatment, but there was significantly more improvement in the electromagnetic field group (32.05\% and $15.58 \%$ vs $1.93 \%$ and $3.24 \%$, respectively, for CWT group). Subjects in both groups improved in their $\mathrm{BMC}$ and $\mathrm{BMD}$ of trochanter after treatment, but there was significantly more increase in BMC and BMD in the electromagnetic field group $(21.25 \%$ and $20.31 \%$ vs $1.36 \%$ and $2.58 \%$, respectively, for CWT group). The BMD of Ward's triangle increased in both groups, but with more significant 
Table 3 Descriptive statistics of BMC and BMD for both groups pre- and posttreatment

\begin{tabular}{|c|c|c|c|}
\hline Variables & Group & $\begin{array}{l}\text { Pretreatment } \\
\text { (mean } \pm \text { SD) }\end{array}$ & $\begin{array}{l}\text { Posttreatment } \\
\text { (mean } \pm \text { SD) }\end{array}$ \\
\hline \multirow[t]{2}{*}{ BMC of neck of femur (g) } & Electromagnetic field & $2.87 \pm 0.52$ & $3.8 \pm 0.41$ \\
\hline & Circuit weight training & $2.79 \pm 0.42$ & $2.85 \pm 0.44$ \\
\hline \multirow[t]{2}{*}{ BMD of neck of femur $\left(\mathrm{g} / \mathrm{cm}^{2}\right)$} & Electromagnetic field & $0.77 \pm 0.05$ & $0.9 \pm 0.02$ \\
\hline & Circuit weight training & $0.74 \pm 0.09$ & $0.76 \pm 0.08$ \\
\hline \multirow[t]{2}{*}{ BMC of trochanter (g) } & Electromagnetic field & $7.01 \pm 0.93$ & $8.5 I \pm 0.52$ \\
\hline & Circuit weight training & $6.67 \pm 0.94$ & $6.76 \pm 0.99$ \\
\hline \multirow[t]{2}{*}{ BMD of trochanter $\left(\mathrm{g} / \mathrm{cm}^{2}\right)$} & Electromagnetic field & $0.64 \pm 0.07$ & $0.78 \pm 0.05$ \\
\hline & Circuit weight training & $0.62 \pm 0.06$ & $0.64 \pm 0.06$ \\
\hline \multirow[t]{2}{*}{ BMD of Ward's triangle $\left(\mathrm{g} / \mathrm{cm}^{2}\right)$} & Electromagnetic field & $0.56 \pm 0.1$ & $0.74 \pm 0.07$ \\
\hline & Circuit weight training & $0.52 \pm 0.09$ & $0.54 \pm 0.09$ \\
\hline \multirow[t]{2}{*}{ BMC of L2 (g) } & Electromagnetic field & $12.9 \pm 2.27$ & $|5.24 \pm 1|$. \\
\hline & Circuit weight training & $\mid 2.21 \pm 1.42$ & $12.26 \pm 1.42$ \\
\hline \multirow[t]{2}{*}{ BMD of L2 $\left(\mathrm{g} / \mathrm{cm}^{2}\right)$} & Electromagnetic field & $0.93 \pm 0.16$ & $1.24 \pm 0.15$ \\
\hline & Circuit weight training & $0.88 \pm 0.18$ & $0.9 \pm 0.17$ \\
\hline \multirow[t]{2}{*}{ BMC of L3 (g) } & Electromagnetic field & $13.96 \pm 2.52$ & $17.27 \pm 1.58$ \\
\hline & Circuit weight training & $|3.2| \pm 2.0 \mid$ & $13.28 \pm 2.0$ \\
\hline \multirow[t]{2}{*}{ BMD of L3 $\left(\mathrm{g} / \mathrm{cm}^{2}\right)$} & Electromagnetic field & $0.96 \pm 0.13$ & $1.2 \pm 0.05$ \\
\hline & Circuit weight training & $0.92 \pm 0.15$ & $0.94 \pm 0.15$ \\
\hline \multirow[t]{2}{*}{ BMC of L4 (g) } & Electromagnetic field & $|5.88 \pm 3.1|$ & $21.53 \pm 2.47$ \\
\hline & Circuit weight training & $14.75 \pm 3.24$ & $14.78 \pm 3.27$ \\
\hline \multirow[t]{2}{*}{ BMD of L4 $\left(\mathrm{g} / \mathrm{cm}^{2}\right)$} & Electromagnetic field & $0.98 \pm 0.16$ & $1.26 \pm 0.06$ \\
\hline & Circuit weight training & $0.93 \pm 0.16$ & $0.95 \pm 0.16$ \\
\hline
\end{tabular}

Abbreviations: SD, standard deviation; BMC, bone mineral content; BMD, bone mineral density.

increase in the electromagnetic field group (32.14\%) than in the CWT group (4.03\%).

Concerning the BMC and BMD of L2, L3, and L4, subjects in both groups improved significantly after treatment, but posttreatment scores were significantly different between the two groups for these variables, with electromagnetic field group showing better improvement $(18.06 \%$ and $32.25 \%$ for $\mathrm{L} 2 \mathrm{BMC}$ and $\mathrm{BMD} ; 23.63 \%$ and $23.95 \%$ for $\mathrm{L} 3 \mathrm{BMC}$ and BMD; $35.57 \%$ and $27.55 \%$ for $\mathrm{L} 4 \mathrm{BMC}$ and $\mathrm{BMD}$ ) than CWT group $(0.4 \%$ and $2.27 \%$ for $\mathrm{L} 2 \mathrm{BMC}$ and $\mathrm{BMD}$; $0.53 \%$ and 2.5 for L3 BMC and BMD; $0.24 \%$ and $2.58 \%$ for $\mathrm{L} 4 \mathrm{BMC}$ and $\mathrm{BMD})$.

\section{Discussion}

In this study, both the electromagnetic field and the CWT exercises were found to improve BMC and BMD of femoral neck, trochanter, Ward's triangle, and lumbar spine (L2-L4) in elderly women after 12 weeks. But the electromagnetic field proved to be superior to CWT exercises.

The improvement of BMC and BMD after electromagnetic field exposure could be attributed to its piezoelectric effect on bone cells, which stimulates calcium deposition in bone. This is supported by the findings of Carpenter and Ayrapntyan, ${ }^{23}$ who concluded that the application of electromagnetic field results in the flow of ionic electric current in bone tubules which acts as an action potential to bone marrow to generate blood and collect calcium. These electrical impulses direct bone growth and the formation of bone cells through calcium deposition.

Results of our study are in agreement with those of Darendeliler et $\mathrm{al}^{24}$ who proposed a number of different mechanisms by which electromagnetic field affects bone tissue: first, it has been shown to stimulate calcification of the fibrocartilage. Second, the increased blood supply that arises due to the effect of electromagnetic field on ionic calcium channels has been implicated as a reason for improved bone healing. Third, electromagnetic field has been suggested as having an inhibitory effect on the resorption phase on bone repair, leading to the early formation of osteoids. A fourth mechanism by which electromagnetic field is thought to have an effect on bone repair is its influence on increasing the rate of bone formation by osteoblasts.

Furthermore, several cellular mechanisms, including increases in growth factors, increases in mineralization, angiogenesis, collagen production, and endochondral ossification, result from electromagnetic field stimulation. Also, it has been shown that there is a decreased osteoclastic activity following electromagnetic field exposure. ${ }^{25}$ The neurophysiological effects of PEMF on bone tissue has been explained by Selvam et $\mathrm{al}^{26}$ who stated that PEMF has been shown to positively 
Table 4 Results of a $2 \times 2$ mixed-model MANOVA and univariate ANOVA for BMC and BMD

\begin{tabular}{|c|c|c|}
\hline Source of variance & $F$-value & $P$-value \\
\hline \multicolumn{3}{|l|}{ MANOVA } \\
\hline Group & 3.66 & $0.007^{*}$ \\
\hline Time & 106.18 & $<0.000 I^{*}$ \\
\hline Time $\times$ group & 101.09 & $<0.000 I^{*}$ \\
\hline \multicolumn{3}{|l|}{ BMC of neck of femur } \\
\hline Between subjects (group) & 10.68 & $0.003^{* *}$ \\
\hline Within subjects (time) & 115.04 & $<0.000 I^{* *}$ \\
\hline Time $\times$ group & 90.97 & $<0.000 I^{* *}$ \\
\hline \multicolumn{3}{|l|}{ BMD of neck of femur } \\
\hline Between subjects (group) & II.I & $0.002^{* *}$ \\
\hline Within subjects (time) & 216.23 & $<0.000$ I** \\
\hline Time $\times$ group & 98.12 & $<0.000 I^{* *}$ \\
\hline \multicolumn{3}{|l|}{$\mathrm{BMC}$ of trochanter } \\
\hline Between subjects (group) & 11.25 & $0.002^{* *}$ \\
\hline Within subjects (time) & 121.7 & $<0.000 I^{* *}$ \\
\hline Time $\times$ group & 95.18 & $<0.0001 * *$ \\
\hline \multicolumn{3}{|l|}{ BMD of trochanter } \\
\hline Between subjects (group) & 13.21 & $0.00 \mathrm{I} * *$ \\
\hline Within subjects (time) & 205.45 & $<0.000 I^{* *}$ \\
\hline Time $\times$ group & 126.56 & $<0.000 I^{* *}$ \\
\hline \multicolumn{3}{|l|}{ BMD of Ward's triangle } \\
\hline Between subjects (group) & II.87 & $0.002 * *$ \\
\hline Within subjects (time) & 149.14 & $<0.000 I^{* *}$ \\
\hline Time $\times$ group & 93.14 & $<0.000 I^{* *}$ \\
\hline \multicolumn{3}{|l|}{$B M C$ of $L 2$} \\
\hline Between subjects (group) & 10.53 & $0.003 * *$ \\
\hline Within subjects (time) & 46.94 & $<0.000 I^{* *}$ \\
\hline Time $\times$ group & 43.42 & $<0.000$ I** \\
\hline \multicolumn{3}{|l|}{$B M D$ of $L 2$} \\
\hline Between subjects (group) & 10.59 & $0.003 * *$ \\
\hline Within subjects (time) & 395.63 & $<0.000 I^{* *}$ \\
\hline Time $\times$ group & 316.95 & $<0.000 I^{* *}$ \\
\hline \multicolumn{3}{|l|}{$B M C$ of $L 3$} \\
\hline Between subjects (group) & 10.43 & $0.003 * *$ \\
\hline Within subjects (time) & 112.05 & $<0.000 I^{* *}$ \\
\hline Time $\times$ group & 102.87 & $<0.000 I^{* *}$ \\
\hline \multicolumn{3}{|l|}{$B M D$ of $L 3$} \\
\hline Between subjects (group) & 10.89 & $0.003 * *$ \\
\hline Within subjects (time) & 95.63 & $<0.000 I^{* *}$ \\
\hline Time $\times$ group & 64.59 & $<0.000 I^{* *}$ \\
\hline \multicolumn{3}{|l|}{ BMC of L4 } \\
\hline Between subjects (group) & 12.7 & $0.001 * *$ \\
\hline Within subjects (time) & 434.46 & $<0.000$ I** \\
\hline Time $\times$ group & 423.27 & $<0.000 I^{* *}$ \\
\hline \multicolumn{3}{|l|}{ BMD of L4 } \\
\hline Between subjects (group) & 12.23 & $0.002 * *$ \\
\hline Within subjects (time) & 125.99 & $<0.0001 * *$ \\
\hline Time $\times$ group & 87.74 & $<0.000 I^{* *}$ \\
\hline
\end{tabular}

Notes: *Significant at $\alpha=0.05$; **Significant with Bonferroni-corrected $\alpha=0.0045$. Abbreviations: MANOVA, multivariate analysis of variance; ANOVA, analysis of variance; $\mathrm{BMC}$, bone mineral content; $\mathrm{BMD}$, bone mineral density.

affect enzyme-based processes at the cellular level and stimulate growth factors involved in cellular repair and bone formation. Every cell membrane carries an electromagnetic charge, and PEMF alters this charge by causing the movement of ions across the cell membrane. PEMF has been shown to exert an anti-inflammatory effect through restoration of plasma membrane calcium ATPase activity.

Also, results of this study are supported by the findings of Richard et $\mathrm{al}^{27}$ who reported that in the moist surroundings of living bone, small piezoelectric potentials are rapidly caused by mechanical deformation. At physiological conditions, mechanical stress-generated potentials are formed by different mechanisms, including 1) the streaming potential, which is the electric potential difference between a liquid and a porous solid through which it is forced to flow; or 2) the electrokinetic processes, ie, the movement of ions because of fluid motion through the bone. The electromagnetic fields caused by these reactions are able to penetrate tissue and the magnetic field part can induce electric currents in the bone or muscle tissue by Faraday coupling.

The improvement in $\mathrm{BMC}$ and $\mathrm{BMD}$ of the treated areas can also be attributed to the effect of PEMFs on the increase in BM in osteoporotic patients, which is caused by the influence of binding to receptors at the cell surface, which in turn can influence the cellular metabolism and stimulate growth, leading to an improvement in the alignment of trabeculae and cartilage. This is consistent with the conclusion of Fitzsimmans et $\mathrm{al}^{28}$ who reported that the PEMFs could also influence the gating mechanism that controls the membrane concentration in lymphocytes and is capable of increasing net calcium flux in the transport of various types of ions such as calcium. They also concluded that PEMFs can increase the calcium human osteoblast cells.

The biological basis of the effects of magnetic fields on cells is highly complex. In an ideal cell at rest, proteins are distributed evenly over the membrane, but in the presence of an electric field crossing the membrane, they undergo electrophoretic attraction or repulsion, tending to shift toward poles which the cell presents in the directions of electric field. Therefore, the cell membrane, by virtue of its bioelectrical properties, is the site where influences of magnetic fields are most likely to be exerted. These results may be attributed to the following mechanisms proposed by Olu et $\mathrm{al}^{29}$ who reported that many of the physicochemical effects inside the tissue depend on the cellular membrane condition, as well as on its mechanical deformations and electrochemical potential. These membrane characteristics are strongly determined by the outer conditions, such as the temperature and ion concentrations in the aqueous solution surrounding the membranes. It is obvious that any outer stimulus such as magnetic stimulation that could affect these outer conditions will affect the cellular membrane status through optical nonhomogeneity factor, leading to an imbalance of some 
process at the membrane level such as the osmotic pressure on the membrane, which can lead to its deformation.

Also, Jacobson et $\mathrm{al}^{30}$ reported that magnetic fields produce piezoelectricity through the intracellular matrix, converting electromagnetic oscillations to mechanical vibration to induce molecular vibrations of frequencies responsible for biological amplifications of extremely weak triggers at the membrane surface. Piezoelectricity may be the common denominator for the specific actions of the various nonionizing, order-inducing biological effects. Piezoelectric mechanisms may be present in all physiological processes. Various structures are thought to be piezoelectric, including bone tissue, blood vessel walls, and collagen fibers.

Decreased physical activity was considered one of the main causes that can develop decreased BMD in geriatric subjects. Therefore, the improvement in BMD in the study group could be attributed to the increase in physical activity as a result of PEMF exposure, which plays an important role in subsiding of pain. This is in agreement with the findings of Weintraub, ${ }^{31}$ who reported that magnetic field influences the small $\mathrm{C}$ fibers.

Furthermore, magnetic field delivers a reversible bar for sodium-dependent action potential firing and calciumdependent responses to the aggravation. ${ }^{32}$ An alternate perspective study clarified that the magnetic field controls pain through reduction of pain fiber excitability or presynaptic inhibition. ${ }^{33}$ The magnetic field produces conformational alteration in neuronal membrane or ion channel. Several mechanisms act together regarding the time needed for the effect on action potentials, such as decrease in channel phosphorylating enzymes activity. ${ }^{34}$ Also, Adey ${ }^{35}$ reported that pulsed magnetic fields can modulate the actions of hormones, antibodies, and neurotransmitters at surface receptor sites of a variety of cell types.

Jacobson et $\mathrm{a}^{30}$ stated that the effect of magnetic field extends to structures such as connective tissue, muscles, and organs, thus producing decreased inflammation, improved circulation, and diminution of pain and hence improved mobility of joints. These results are in agreement with those of Hinman et $\mathrm{al}^{33}$ who reported that the application of magnetic field to the musculoskeletal problems can reduce pain, decrease joint swelling, and enhance movement.

Trock $^{36}$ also revealed that application of magnetic field might promote cellular and subcellular molecular effects within damaged cartilaginous and bony tissues. Pulsed magnetic field can stimulate both bone and cartilage cells, thus improving joint function and joint integrity due to improved bone and cartilage maintenance and repair.
Results of our study demonstrated that the magnetic field has a positive effect on BMD through increasing calcium deposition in bones and improving the activity of osteoblasts; this can be explained by the findings of Hosokwa et $\mathrm{al}^{37}$ who revealed that the mechanism of magnetic field that causes calcium to precipitate in bone tissue is not related to sex hormones and can promote the growth and control the activity of osteoblast cells, resulting in an increase of overall bone density. It accelerates the formation of bone collagen in combination with calcium, in addition to effectively promoting fixation of dissociated intracellular calcium and preventing release of calcium from bone cells. Neil ${ }^{38}$ also reported that pulsed magnetic field exposure might be useful in the treatment of bone fracture, spinal fusion, bone formation, and bone transplant, which is in agreement with the findings of Mandronero, ${ }^{39}$ who concluded that magnetic field enhances bone tissue formation. Bone mineral densities of the treated radii measured by densitometry increased significantly in the intermediate area of the field during the exposure period of PEMFs.

Low-frequency magnetic fields can increase calcium concentration in lymphocytes in the same manner as a physiological stimulus such as antibodies, and increase net calcium flux in human osteoblast-like cells. The increase in net calcium flux is frequently dependent on magnetic field, which induces a maximum potential gradient across cell membrane. ${ }^{28}$ This is in agreement with the findings of Li et $\mathrm{al}^{40}$ who reported that the physical-chemical interactions between biological tissues and PEMF may occur outside the cell and then propagate and amplify through conventional or novel signal transduction pathways. A stimulation of transduction pathways is apparent by PEMF, resulting in increased cytosolic $\mathrm{Ca}^{2+}$ and activation of calmodulin, which finally stimulate osteoblastic cell proliferation.

This is supported by the findings of Potzl,${ }^{41}$ who reported that the therapy with electromagnetic fields is a complex method which can improve metabolism of bone tissues and its structures through slowing or preventing loss of bone because of the re-creation of the piezoelectric effect and building of bone substance due to the activation of calcium metabolism and stimulation of calcium deposits in the bone, indirect effects of PEMF due to regulation of the hormone system, which plays a crucial role in regulating the metabolism of minerals, and improvement of overall well-being and increased activity will have a positive impact on symptoms of osteoporosis.

The improvement in BMC and BMD after CWT exercises could be attributed to the mechanical loads applied to bones which create strain. This strain is transmitted to the bone 
cells (osteoblasts, bone lining cells, and osteocytes), which are well suited to sense load changes due to their physical connections. In response to mechanical strain, there is an increase in cell metabolism and collagen synthesis. ${ }^{42}$ This is in agreement with the findings of Neil and Ronald, ${ }^{43}$ who stated that resistance training has recently been recognized as a useful therapeutic tool for the treatment of a number of chronic diseases. Similar to aerobic exercise, resistance training has been reported to enhance insulin sensitivity, daily energy expenditure, and quality of life. Furthermore, resistance training has the potential for increasing muscle strength, lean muscle mass, and BMD, which could enhance functional status and glycemic control and assist in the prevention of sarcopenia and osteoporosis.

Also, our results are consistent with those of Meka et $\mathrm{al}^{44}$ who proved that resistance training has profound beneficial effects on improving muscle strength and endurance, preventing osteoporosis and improving the quality of life both in the healthy and cardiovascular patients, including women and heart failure patients. Therefore, resistance training should be regarded as a complementary fitness program rather than as a substitute to endurance training. Our findings were also consistent with other reviews also reporting a significant effect of exercise on femoral neck BMD. ${ }^{45-47}$ Also, our results are in agreement with those of an earlier meta-analysis by Martyn-St James and Carroll, ${ }^{48}$ who observed that structured exercise protocols of combined loading and exercise programs of low impact have the potential for preserving BMD at the lumbar spine and femoral neck in postmenopausal women.

Our results are supported by the findings of ChodzkoZajko et $\mathrm{al}^{49}$ who concluded that aerobic exercise training may be effective in counteracting age-related declines in $\mathrm{BMD}$ and that high-intensity resistance exercise training preserves or improves BMD. Beneficial effects of exercises are also supported by the findings from a meta-analysis of RCTs by Marques et $\mathrm{al}^{50}$ that support the efficacy of exercise in increasing the lumbar spine and femoral neck BMD in older adults.

Epidemiological studies by the American College of Sport Medicine ${ }^{51}$ support our findings as they agree that women who have been able to maintain higher levels of physical activity have a lower incidence of hip fractures. Factors such as frequent muscle loading, faster walking speeds, more productive activity, increased participation in outdoor activities, and greater time standing and moving about were all associated with a reduced fracture incidence in these studies. Our findings are also supported by those of Rhodes et $\mathrm{al}^{52}$ and Romero et $\mathrm{al}^{53}$ who proved that resistance training has been shown to be more effective for increasing BMD. Also results are also in concordance with those of Specker and Binkley ${ }^{54}$ who proved that moderate physical activity in the pre- and peripubertal period could enhance BMC accrual with a magnitude that, if retained into old age, would actually reduce the number of fragility fractures.

\section{Conclusion}

Thus, both electromagnetic field therapy and CWT program had an effect in increasing BMC and BMD in elderly women, but the electromagnetic field therapy was found to have a superiority effect.

\section{Author contributions}

All authors contributed to the study, including data collection, exercise protocol application, carrying out the study design, drafting the manuscript, and statistical analysis.

\section{Disclosure}

The authors report no conflicts of interest in this work.

\section{References}

1. Singh M. Benefits of exercise and dietary measures to optimize shifts in body composition with age. Asia Pacific J Clin Nutr. 2002;11(Suppl): S642-S665.

2. Spadaro J, Bergstrom W. In vivo and in vitro effects of a pulsed electromagnetic field on net calcium flux in rat calvarial bone. Calcif Tissue Int. 2002;70:496-502.

3. Chang K, Chang W. Pulsed electromagnetic fields prevent osteoporosis in an ovariectomized female rat model: a prostaglandin E2-associated process. Bioelectromagnetics. 2003;24:189-198.

4. Fini M, Torricelli P, Giavaresi G, et al. Effect of pulsed electromagnetic field stimulation on knee cartilage, subchondral and epyphiseal trabecular bone of aged Dunkin Hartley guinea pigs. Biomed Pharmacother. 2008;62:709-715.

5. González-Riola J, Pamies J, Hernández E, et al. Influence of electromagnetic fields on bone mass and growth in developing rats: a morphometric, densitometric, and histomorphometric study. Calcif Tissue Int. 1997;60:533-537.

6. Akca K, Sarac E, Baysal U, Fanuscu M, Chang T, Cehreli M. Micromorphologic changes around biophysically stimulated titanium implants in ovariectomized rats. Head Face Med. 2007;3:28.

7. Bonhomme-Faivre L, Macé A, Bezie Y, et al. Alterations of biological parameters in mice chronically exposed to low-frequency $(50 \mathrm{~Hz})$ electromagnetic fields. Life Sci. 1998;62:1271-1280.

8. Güler G, Türközer Z, Seyhan N. Electric field effects on Guinea pig serum: the role of free radicals. Electromagn Biol Med. 2007;26: 207-223.

9. Khanduja K, Syal N. Sinusoidal electromagnetic field of $50 \mathrm{hz}$ helps in retaining calcium in tibias of aged rats. Indian J Exp Biol. 2003;41: 201-204.

10. Kim S, Lee H, Choi S. Toxicity bioassay in Sprague Dawley rats exposed to $20 \mathrm{kHz}$ triangular magnetic field for 90 days. Bioelectromagnetics. 2006;27:105-111.

11. Tesch P. Training for bodybuilding. In: Komi P, editor. Strength and Power in Sport. Boston, MA: Blackwell Scientific Publications; 1992: 370-381. 
12. Brentano M, Cadore E, Da Silva E, et al. Physiological adaptations to strength and circuit training in postmenopausal women with bone loss. J Strength Cond Res. 2008;22(6):1816-1825.

13. Camargo M, Stein R, Ribeiro J, Schvartzman P, Rizzatti M, Schaan B. Circuit weight training and cardiac morphology: a trial with magnetic resonance imaging. Br J Sports Med. 2008;42(2):141-145.

14. Gettman L, Ayres J, Pollock M, Durstine J, Grantham W. Physiologic effects on adult men of circuit strength training and jogging. Arch Phys Med Rehabil. 1979;60:115-120.

15. Harber M, Fry A, Rubin M, Smith J, Weiss L. Skeletal muscle and hormonal adaptations to circuit weight training in untrained men. Scand J Med Sci Sports. 2004;14(3):176-185.

16. Nelson M, Fiatarone M, Morganti C, Trice I, Greenberg R, Evans W. Effects of high-intensity strength training on multiple risk factors for osteoporotic fractures. A randomized controlled trial. JAMA. 1994; 272(24):1909-1914.

17. Jonsson B. Life Style and Fracture Risk [thesis]. Sweden: University of Lund; 1993.

18. Eickhoff JA, Molczyk L, Gallagher JC, De Jong S. Influence of isotonic, isometric and isokinetic muscle strength on bone mineral density of the spine and femur in young women. Bone Miner. 1993;20:201-209.

19. Calatayud J, Borreani S, Moya D, Colado JC, Triplett NT. Exercise to improve bone mineral density. Strength Cond J. 2013;35(5):70-74.

20. Welkowitz J, Ewen R, Cohen J. Introductory Statistics for the Behavioral Sciences. 3rd ed. San Diego, CA: Harcourt Brace Jovanovich; 1982.

21. Cummings S, Melton L. Epidemiology and outcomes of osteoporotic fractures. Lancet. 2002;359(9319):1761-1767.

22. Yavari A, Najafipoor F, Aliasgarzadeh A, Niafar M, Mobasseri M Effect of aerobic exercise, resistance training or combined training on glycemic control and cardio-vascular risk factors in patients with type 2 diabetes. Biol Sport. 2012;29(2):135-143.

23. Carpenter D, Ayrapntyan S. Biological Effects of Electric and Magnetic Fields. Vol 15. San Diego, CA: Academic Press; 2004;3-7.

24. Darendeliler M, Darendeliler A, Sinclair P. Effects of static magnetic and pulsed electromagnetic fields on bone healing. Int J Adult Orthodon Orthognath Surg. 2005;12(1):43-53.

25. Piptone N, Scott D. Magnetic pulse treatment for knee osteoarthritis: a randomized, double-blind, placebo-controlled study. Curr Med Res Opin. 2001;17(3):190-196.

26. Selvam R, Ganesan K, Narayana Raju K, Gangadharan A, Manohar B, Puvanakrishnan R. Low frequency and low intensity pulsed electromagnetic field exerts its anti-inflammatory effect through restoration of plasma membrane calcium ATPase activity. Life Sci. 2007;80(26):2403-2410.

27. Richard H, Thomas M, Nurdan O. Electromagnetic effects - from cell biology to medicine. Prog Histochem Cytochem. 2008;43:177-264.

28. Fitzsimmans R, Brown T, Baylink J. Growth factors and electromagnetic fields in bone. Clin Plast Surg. 2005;21(3):401-406.

29. Olu V, Kaplan M, Stepanov V. The non-resonant mechanism of the biostimulating effect concerning the low-intensity laser radiation. Fizicheskaia Meditzing. 1992;2:40-50.

30. Jacobson J, Gorman R, Yamanashi W, Saxena B, Clayton L. "Low amplitude, extremely low frequency magnetic field for the treatment of osteoarthritic knee" a double blind clinical study. Altern Ther Health Med. 2001;7(5):54-64, 66-69.

31. Weintraub M. Magnetic biostimulation in painful diabetic peripheral neuropathy: a novel intervention - a randomized, double-placebo crossover study. Am J Pain Manage. 1999;9(q1):8-17.

32. Holcomb R, Parker R, Harrison M. Biomagnetics in the treatment of human pain-past, present, future. Environ Med. 2000;8:24-30.

33. Hinman M, Ford J, Heyl H. "Effects of static magnets on chronic knee pain and physical function" a double-blind study. Altern Ther Health Med. 2002;8(4):50-55.

34. Segal N, Huston J, Fuch H, Holcomb R, Mcleod M. Efficacy of a static magnetic device against knee pain associated with inflammatory arthritis. J Clin Rheumatol. 1999;5:302-304.
35. Adey W. Physiological signaling across cell membranes and cooperative influences of extremely low frequency electromagnetic fields. In: Frohlich H, editor. Biological Coherence and Response to External Stimuli. New York, NY: Springer-Verlag; 1999.

36. Trock D. Electromagnetic field and magnet investigational treatment for musculoskeletal disorders. Rheum Dis Clin North Am. 2004;26(1): 51-62.

37. Hosokwa K, Yamaguchi H, Kashimoto H. Effects of ELF magnetic fields on regulation of calcium concentration in cultured osteoblasts. In: The Bioelectromagnetics Society Twenty First Annual Meeting \{C \}. Munich, Germany: The Technical University; 2000.

38. Neil K. Electrical stimulation of spinal fusion: a scientific and clinical update. Spine J. 2002;2:145-150.

39. Mandronero A. Influence of magnetic fields on calcium salts crystal formation: an explanation of the PEMF technique for bone healing Biomed Eng. 2000;12(5):410-414.

40. Li J, Lin J, Liu H. Comparison of ultrasound and electromagnetic field effects on osteoblast growth. Ultrasound Med Biol. 2006;32: 769-775.

41. Potzl W. Does immobilization after radiofrequency-induced shrinkage influences the biomechanical properties of collagenous tissue. $\mathrm{Am}$ J Sports Med. 2004;32:681-687.

42. Rossouw J, Anderson G, Prentice R. Risks and benefits of estrogen plus progestin in healthy postmenopausal women: principal results from the Women's Health Initiative randomized controlled trial. JAMA. 2002; 288:321-333.

43. Neil D, Ronald C. Resistance training and type 2 diabetes considerations for implementation at the population level. Diabetes Care. 2006;29(8): 1933-1941.

44. Meka N, Katragadda S, Cherian B, Arora R. Endurance exercise and resistance training in cardiovascular disease. Ther Adv Cardiovasc Dis. 2008; 2(2):115-121.

45. Martyn-St James M, Carroll S. High-intensity resistance training and postmenopausal bone loss: a meta-analysis. Osteoporos Int. 2006; 17(8):1225-1240

46. Martyn-St James M, Carroll S. Meta-analysis of walking for preservation of bone mineral density in postmenopausal women. Bone. 2008; 43(3):521-531.

47. Wallace B, Cumming R. Systematic review of randomized trials of the effect of exercise on bone mass in pre- and postmenopausal women. Calcif Tissue Int. 2000;67(1):10-18.

48. Martyn-St James M, Carroll S. A meta-analysis of impact exercise on postmenopausal bone loss: the case for mixed loading exercise programs. Br J Sports Med. 2009;43(12):898-908.

49. Chodzko-Zajko W, Proctor D, Fiatarone Singh M, et al. American College of Sports Medicine position stand. Exercise and physical activity for older adults. Med Sci Sports Exerc. 2009;41(7):1510-1530.

50. Marques E, Mota J, Carvalho J. Exercise effects on bone mineral density in older adults: a meta-analysis of randomized controlled trials. Age. 2012;34(6):1493-1515.

51. American College of Sport Medicine position stand on osteoporosis and exercise. Med Sci Sports Exerc. 1995;27(4):i-vii.

52. Rhodes E, Martin A, Taunton J, Donnelly M, Warren J, Elliot J. Effects of one year of resistance training on the relation between muscular strength and bone density in elderly women. Br J Sports Med. 2000;34: $18-22$

53. Romero-Arenas S, Blazevich A, Martinez-Pascual M, et al. Effects of high-resistance circuit training in an elderly population. Exp Gerontol. 2013;48(3):334-340.

54. Specker B, Binkley T. Randomized trial of physical activity and calcium supplementation on bone mineral content in 3- to 5-year-old children. J Bone Miner Res. 2003;18:885-892. 


\section{Publish your work in this journal}

Clinical Interventions in Aging is an international, peer-reviewed journal focusing on evidence-based reports on the value or lack thereof of treatments intended to prevent or delay the onset of maladaptive correlates of aging in human beings. This journal is indexed on PubMed Central, MedLine,

CAS, Scopus and the Elsevier Bibliographic databases. The manuscript management system is completely online and includes a very quick and fair peer-review system, which is all easy to use. Visit http://www.dovepress. com/testimonials.php to read real quotes from published authors.

Submit your manuscript here: http://www.dovepress.com/clinical-interventions-in-aging-journal 